\title{
To Believe or Not to Believe: an Epistemic Exploration of Fake News, Truth, and the Limits of Knowing
}

\author{
Jennifer Rose ${ }^{1}$ iD \\ Published online: 6 December 2019 \\ (C) The Author(s) 2019
}

\begin{abstract}
In the 2016 US presidential election campaign, an online news story broke reporting that 'tens of thousands' of pre-marked ballots had been found in a warehouse in Ohio. The ballots were reportedly marked in favor of Hillary Clinton and were to be counted alongside real election ballot boxes. The story contained a picture of the ballot boxes along with the individual who supposedly discovered the ballots. The story was false; however, before its falseness was exposed, it went viral and was viewed by the media as having affected the outcome of the election in favour of Donald Trump. While the deceit of the creator of this fake news should be of great concern, the perilousness of fake news to the corrosion of democracy is substantial. In this paper, I explore what it means to be an online news consumer in relation to the magnitude of the problem of fake news. I examine what it means for online news consumers to acquire knowledge and the pitfalls they experience in a fake news online environment. I add another layer of analysis through the exploration of how online news consumers determine truth and discuss the boundaries of determining the truth in fake news online environments. I conclude that in a fake news online environment, acquiring knowledge for democratic participation is dubious. Determining the truth of fake news stories can be uncertain, and when combined with limited opportunities to gain knowledge, online news consumers are in a conundrum of what to believe. I conclude with the suggestion that one-way education ought to assist online news consumers in understanding the limits of their epistemological stances in relation to fake news in online environments as an outset to assist citizens to become better online news consumers, so they have the option to enact democracy through increased epistemic volition.
\end{abstract}

Keywords Fake news · Truth · Epistemology $\cdot$ Limits of knowing

Jennifer Rose

jrose02@qub.ac.uk

1 Queen's University Belfast, Belfast, UK 


\section{Introduction}

In early fall, in 2016, during the US presidential election campaign, Donald Trump, who was reportedly behind in the election polls, publically announced to a Columbus Ohio crowd that he was concerned with the probity of the election process declaring, 'I'm afraid the election is going to be rigged, I have to be honest' (Shane 2017). While Trump repeatedly expressed the belief that the general election was unfairly rigged in Hillary Clinton's favour, he did not offer any evidence to support his claim (Shane 2017; Berenson 2016). On October 3rd, 2016, a new college graduate, Cameron Harris, composed and published a news story online ${ }^{1}$ titled: 'BREAKING: Tens of thousands' of fraudulent Clinton votes found in Ohio warehouse'. The story charged the Democratic Party with pre-marking ballots in support of Hilary Clinton that were to be distributed and counted with real election ballots. In support of its claims, the story contained a photograph portraying a stack of election boxes that were marked 'Ballot Box' and the worker, who reportedly found the ballot boxes, inside a warehouse in Ohio. The photograph served as evidence for the alleged ballot fraud that the Democratic Party was charged with perpetrating. The story went viral, reportedly reaching 6.1 million people, and was viewed by the media as giving Trump a boost in votes, thereby impacting on the outcome of the election (Garcia and Lear, 2016). However, the story and the photograph were false. Cameron Harris admitted to fabricating the story and photoshopping the photograph, which resulted in a fake news story that undermined, as I shall describe it in this paper, online news consumers' ability to gain knowledge and detect the truth. The consequence was, arguably, corrosion of democratic values, such as the obligation to promote the common good, respecting individual rights, justice, and truth, distorting the flow of knowledge necessary to make informed decisions, and deliberately undermining a democratic election. Fake news surely requires scrutiny of its illusionary and deceitful nature if citizens are to have a choice in enacting their democratic values or not.

In this paper, I explore the depth of the problem of fake news in relation to what it means to be an online news consumer. I consider the nature of knowledge and what it means to be consumer of news in an online environment. First, I attend to traditional analytical understandings of knowledge, such as justified true belief concerning fake news and what it means for online news consumers' ability to acquire knowledge. The limits to acquiring knowledge are revealed when diligent news consumers attempt to seek knowledge in a fake news online environment. Next, I consider the nature of truth through an exploration of two theories of truth and what they mean for consumers accessing news from an online environment. I discuss the implications of seeking truth as an epistemic good online and determine that ascertaining truth in a fake news environment is contextual. I suggest that due to their limited knowing, diligent online news consumers may use their perspectival and contextual beliefs in a universal manner when determining truth, which can impede their ability to navigate the complex web of deceitful or misleading information, reduce false beliefs, and become better online news consumers. Through this discussion of the epistemological complexity of being a consumer of news online, I suggest that education ought to intervene to help consumers

\footnotetext{
${ }^{1}$ Cameron Harris published the article on a website domain he purchased: www.christiantimesnewspaper.com
} 
of news understand the limits of their own epistemological stances in relation to fake news online. Understanding what one can and cannot know in online environments may increase consumers' epistemic volition so they can enact their democratic values.

\section{The Depth of the Problem of Fake News}

The phenomenon of fake news is not new. Vojak (2017) reminds us of the long history of fake news in the USA. In $1874^{2}$, The New York Herald published an article claiming that animals had been freed from the Central Park Zoo and were rampaging through New York City, killing dozens of people. There was a small disclaimer at the end of the article stating that the article was a complete fabrication; it was a hoax thought up by the writer. However, many New Yorkers, who did not read to the end, panicked. Fake news continued, and throughout the 1960s-1970s, with the rise of celebrity culture in the USA, tabloids spreading false information for entertainment purposes increased (Siegal n.d.). Fake news is not only about complete fabrications or created for entertainment purposes. Dentith (2017) observes that fakes news, and its counterparts, 'alternative facts' and 'disinformation,' can play a central role in political campaigns and regimes. During the 2016 US presidential election, a resurgence of fake news occurred in public discourse with more than troubling social consequences. Online news consumers' were, and are, confronted with threats of fettered access to accurate information for decision making. As seen in the fake news story of the 'fraudulent ballots', we may not have to look too deep or too far to see the far-reaching political and detrimental effects of fake news. However, what is fake news?

\section{What Is Fake News?}

Klein and Wueller (2017: 6) define fake news as 'publications that are intentionally or knowingly false'. In this view, the statements in fake news publications are fabricated, untrue, and not believed to be true by the publishers. Gelfert (2018: 100) points out, however, that fake news is not necessarily equated with false news or news that is completely fabricated. Some fake news publications may 'mix deliberate falsehoods with well-known truths as a means of obfuscation'. In this sense, the audience may be misled without being told falsehoods, but there is an intention to spread misinformation or to deceive and so 'fake news is necessarily tied to the malicious intent of individual human agents' (Gelfert 2018: 97). Dentith (2017: 66) defines fake news as an 'allegation that some story is misleading - it contains significant omissions - or even false-it is a lie-designed to deceive its intended audience'. The ploy of fake news is to report purported facts or facts that are designed to represent the truth. Like Gelfert, Dentith notes that the 'facts' may be entirely false, contain partial truths, or they may lack the context that would undermine the truth of the statement if it was revealed.

However, MacKenzie and Bhatt (2018) point out that fake news is not necessarily an intentional effort to deceive. Citing Frankfurt (1985), fake news can include '[b]razen

\footnotetext{
${ }^{2}$ For details see: 'The Central Park Zoo Escape' at http://hoaxes.org/text/display/the_central_park_zoo_ escape_text/ (Last Accessed March 19th, 2019).
} 
hoaxes, satires, pranks, or parodies...but they need not be slurs on the truth'. The use of these presentational mechanisms of humour and exaggeration is often a tactic to reveal the deception or misrepresentations concealed in real events or social critique. Additionally, the term fake news can be used to undermine the credibility and trustworthiness of news that is indeed 'truthful, factual, and representative of reality' (MacKenzie and Bhatt 2018); that is, fake news can be 'a rhetorical device for shutting down critical reporting' (Gelfert 2018: 85); or it can be a phrase that is used to describe reports that are disliked or viewed as 'unflattering' by public figures (Klein and Wueller 2017: 6). However, to understand the nature of fake news and what it means for online news consumers, my concern is with fake news that gives the appearance of representing the truth, as fake news that attempts to reveal the truth, such as satire, is not an obstruction to knowledge acquisition for online news consumers.

As I will explore, the epistemological magnitude of online fake news is detrimental to knowledge acquisition when online news consumers seek to gain the knowledge they require for democratic decision-making. It may seem evident that fake news is an impediment to knowledge acquisition, or that the appropriate response to such impediments is to encourage online news consumers to fact check, search for alternatives views, or engage in a careful process by which to gain true, justified belief. For by virtue of its name, fake news implies that such news is inauthentic or counterfeit, which, by intuitive appeal, suggests an intentionally mendacious agent. The logical step for a diligent online news consumer would be to seek the truth, check the facts, or adopt a pluralistic view of the epistemic concern. I focus on the diligent online news consumers as we can expect a non-diligent online news consumer to eschew gaining knowledge or, perhaps, to possess particular epistemic vices. As I will discuss next, fact-checking in a fake news era places diligent online news consumers in a precarious position when attempting to acquire knowledge in the wake of pervasive chicanery. What I aim to reveal is that the characteristic of fake news of appearing to represent truth is not merely a fact-checking exercise, an attempt to gain pluralistic views, or necessarily an engagement in the process of being a reliable and diligent online news consumer. To understand why and what it means for online news consumers, I begin by exploring the nature of knowledge and what is required of online news consumers to acquire it.

\section{Seeking Knowledge in a Fake News Era}

Traditional analytical epistemology has proposed that to possess knowledge one must possess justified, true, belief (JTB $)^{3}$ (Audi 2011). For an online news consumer to have knowledge, s/he must believe in the phenomenon under question. For instance, s/he cannot know something if $\mathrm{s} /$ he does not believe it. As such $\mathrm{s} / \mathrm{he}$ cannot say s/he knows it is sunny outside unless $\mathrm{s} / \mathrm{he}$ believes that it is indeed sunny outside. The truth condition requires one to say s/he knows something which s/he must believe is true,

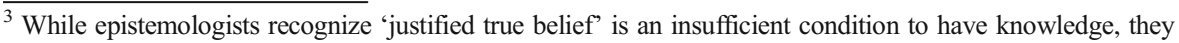
generally agree that justification, truth, and belief are still individually necessary to have knowledge. There is an ongoing debate on what additional conditions are needed to be considered necessary and sufficient to possess knowledge (see Turri (2012) and Zagzebski (1994)). Resultantly, there are boundaries around my epistemic exploration, which entail that I focus on knowledge as justified true belief, and its limitations in exploring fake news.
} 
for $\mathrm{s} /$ he cannot say $\mathrm{s} / \mathrm{he}$ knows it is sunny out when it is indeed not sunny; for one to know it is sunny out, it must be sunny. Finally, s/he must have justification, evidence, or reasons for one's belief. If s/he is to know it is sunny, s/he must have evidence that it is sunny or reasons to believe it is sunny, which s/he may gain through various means. For example, one may directly perceive that it is sunny and possess direct evidence. One may have also seen earlier in the day that the sunrise was bright and the sky was free from clouds, so s/he would have some justification to believe that it is sunny. Or individuals who are visually impaired may infer it is sunny outside by experiencing the warmth of the sun on their skin. On this perspective, if all three of these conditions are met, one will then have knowledge. However, individuals can justify their belief in propositions and deem the propositions as true, when, in fact, the propositions are false (Gettier 1963). Such a phenomenon can occur in a fake news online environment. Let us consider the fraudulent ballot case of fake news to understand what fake news can mean for the online news consumers when they do seek to acquire knowledge.

For online news consumers to possess knowledge in the fraudulent ballot case, they must have justified true belief. We can say that at least some of the 6.1 million online news consumers believed the fraudulent ballot case. It was reported that the case impacted on voters' decision, making Trump a beneficiary of votes, which means that some voters must have believed the story; if they did not believe that the Democratic Party was corrupt, it would surely be contradictory to support Trump. So we can say that some voters possess belief, and if they did not possess belief prima facie, they were at least confronted with evidence to support their belief - the TV pictures.

We now know that the fraudulent ballot case was false; however, let us consider what evidence the voters had access to before the discovery of its falseness. When the story was published, online news consumers were in a position to view the photograph as evidence for the truthfulness of the story. The photograph contained three pieces of evidence available for fact-checking: an Ohio warehouse, a worker, and ballot boxes. Firstly, the warehouse depicted in the photograph was an actual Ohio warehouse that was abandoned (Garcia and Lear 2016). Online news consumers who fact-checked by looking up its geographic location, or who drove to its location, would indeed find the warehouse in question. Secondly, the ballot boxes were also 'real' ballot boxes (Garcia and Lear 2016). Online news consumers who search for images of ballot boxes in any search engine images will find photos of ballot boxes and be able to verify that the ballot boxes in the photo were real ballot boxes. Thirdly, the fact-checker also would see that the worker standing behind the boxes was Randall Prince, which, with a search of the white pages for Columbus Ohio, the fact-checker would quickly learn that there are indeed two people named Randall Prince who reside the surrounding areas of Columbus. In this instance, the fact-checker or diligent online news consumers possess justified belief as they possess good evidence for inferring the truth of the story if they did not already believe the story prima facie. Yet, as we now know, these online news consumers did not know or, as I suggest, did not possess the knowledge of the story, though they possessed justification and strong evidence which enabled them to infer the truth to support their belief. Their belief was based on inference as they were not at the Ohio warehouse, with Randall Price, and the ballots boxes to witness the legitimacy of the photograph. Online news consumers were inferring truth from false premises (Gettier 1963). 
What begins to emerge is that fact-checking in a fake news era can be deeply problematic. As I have just discussed, fake news possesses the characteristics of being designed to deceive knowers (Dentith 2017). Being designed to deceive knowers is to present news that is false but appears true. We might expect a lackadaisical knower to fall prey to the ploys of mendaciousness of fake news. However, as I have illustrated, even a diligent online news consumer who diligently extends one's epistemic and factchecking capabilities to seek the truth may not be able to overcome the inherent deceit of fake news. The obvious solution to this problem of forming beliefs from false premises is to not count beliefs from false premises as knowledge (Zagzebski 1994). One may ask how one can avoid using false premises if they do not know they are false? Herein lies the depth of the problem with fake news. A diligent online news consumer is likely at a pervasive risk of inferring truth from false premises.

However, Goldman (1976) points out that even if one possesses justified true beliefs that have not been inferred from false premises that one may still not have knowledge. Goldman (1976) explains that it is possible for one to justify one's beliefs that are true; however, s/he may have only arrived at truth by sheer luck. Arriving at truth by luck is not possessing knowledge as one must be able to reliably tell the difference between true and false propositions (Goldman, 1976). Said another way, to say that an online news consumer has knowledge of a news story or possesses justified true belief, s/he must be able to reliably discriminate between a fake news story and a real news story. What does Goldman's observation mean for online news consumers in a fake news era?

Let us return to the fraudulent ballot case and consider a diligent online news consumer who correctly identifies the story as false through justified true belief, but in fact, does not know that the story is false. A diligent online news consumer resides in an era of fake news that is intermingled with true news such as a video of Donald Trump degrading women. The diligent online news consumer had seen many allegations of fake news during the 2016 US Election campaign when political party assassination was rampant. A fake news story is not out of place, but neither is a real news story. The 'fraudulent ballot' story breaks and the diligent online news consumer tells her friend that the story is fake before its falseness is revealed. The diligent online news consumer has justified her belief that the story is false because she has inferred from the rise of fake news in the media during the election, that fake news is rampant and she has seen Trump vocalize contradictory messages, which can foster distrust. She is considered diligent as she is seeking truth to the best explanation ${ }^{4}$ (Lipton 2007). Unbeknownst to her, she is also justified in believing the story is false because it is true. She therefore correctly identified the 'fraudulent ballot' story as false, which was a true belief, but she did not know it was false as she could not provide evidence that the story was false if required to do so. In this instance, a diligent online news consumer who possesses a justified true belief that was not inferred from false premises still did not possess knowledge as she arrived at the correct conclusion through luck.

In this section, I have discussed the depth of the problem of fake news concerning a diligent online news consumer and the inert limitations of fake news. A consumer of news online may meet the requirements for knowledge when evaluating fake news, but still not be able to identify false premises when determining justification for believing a

\footnotetext{
${ }^{4}$ When access to the facts is limited, knowers are still considered diligent if they explain their reasoning according to the best explanation. For details see Lipton (2007).
} 
story or not. A diligent consumer of news online also may not possess knowledge if one cannot diligently or reliably tell the difference between a fake or real news story. The diligent online news consumer can justify one's belief through inference from true premises, but not have knowledge if they are unable to know through the provision of evidence the distinction between real and fake news. Consequently, the ability of online news consumers to gain knowledge in an era of fake news is severely limited. While fake news is designed to deceive, the diligent online news consumer has not been considered in relation to fake news to discuss whether or not she can overcome the deceit of fake news to gain knowledge. As discussed through this one example, the inability to gain needed knowledge for the choice to participate in democratic decision making is arduous, and one may still not gain knowledge. Next, I turn to explore assessing the truth of fake news and the problems that arise for knowers when seeking to determine truth.

\section{Truth, Online News Consumers, and Fake News}

In the last section, I discussed the difficulty a diligent online news consumer can encounter when seeking to gain knowledge through the evaluation of fake news. I discussed whether or not one can know, or gain knowledge by justifying one's belief by seeking evidence. In this discussion of truth, I discuss the resources available to a diligent news consumer for assessing whether or not news in question is true or false in an online environment. I do so as for news consumers to gain knowledge would require them to extend beyond the scope of the online environment to verify whether or not the propositions within the fake news story are true by seeking physical evidence. Truth, however, is a nebulous term that has been grappled with for centuries by philosophers (Kirkham 1995). It differs from justification as evidence; as the idea of there being a single truth, an objective truth 'has never been free from controversy' (McIntyre 2018: 6). My intent is not to discuss these historical debates but to suggest that we can learn something from looking at two conventional theories of truth in relation to online news consumers: Russell's correspondence theory of truth and coherence theory of truth.

\section{Internal Beliefs, Truth, and Correspondence with the World of Fake News}

I begin with Bertrand Russell's (Russell, 1912) correspondence theory of truth. Russell's correspondence theory of truth suggests that one has assessed truth if one's belief, and the relationship between the objects of the belief corresponds to the facts in the same relationship external to one's mind. Russell (1912: 10) notes that '[w]e must therefore, if possible, find, in our own purely private experiences, characteristics which show, or tend to show, that there are in the world things other than ourselves and our private experiences'. Russell argues that in assessing truth we ought to look for 'the existence of something independent of us and our perceptions' (13). Further when we establish the correspondence between our internal belief and the external world, this correspondence is filtered through our perception, so we can only know that of the physical world which corresponds with our belief. Russell gives an example of various individuals looking at a coin. The shape of the coin will look different to individuals based on the position of the onlookers relative to the coin. The physical shape of the 
coin remains the same, though the perception differs amongst the individual onlookers. Further, Russell tells us that we can

know only what is required in order to secure the correspondence. That is to say, we can know nothing of what it is like in itself, but we can know the sort of arrangement of physical objects which results from their spatial relations (15).

While we can know the relationship between objects in the external world and our perception, or sense data, in order to establish the correspondence of our own belief with these objects, we cannot know the physical space of these objects. Therefore, physical objects cannot 'be exactly like sense data, yet they may be more or less like' (16). So the truth is merely a correspondence of private belief with the external physical world, but it is not a replica of the physical world as the physical world is filtered through our senses.

What can we learn from Russell's conceptualization of truth concerning knowers and fake news? A knower contemplating whether or not a news story is true will seek to understand whether one's private or internal belief corresponds with the external or physical facts of the fake news story. There may be many beliefs that knowers can hold regarding the two dominant political parties in the 2016 US presidential election. However, I focus on discussing the beliefs of two different knowers: a knower who is pro-Democrat and a knower who is pro-Republican. I do so because these are the two dominant political stances available regardless of the variation of belief within each camp.

Let us begin with Janie, who is pro-Democratic. She has strong reasons to believe in the Democratic Party's values. She fully supports the democratic values that Hillary Clinton espoused. The fraudulent ballot fake news story breaks, and Janie does not believe that the story is true. The facts external to Janie's belief and trust in the Democratic Party suggest that, on the contrary, the Democratic Party is, in fact, corrupt. The external facts, therefore, do not appear to correspond with her belief in the democratic values portrayed in the fake news story. Janie ignores the evidential photograph because she has prior evidence that supports her belief in the integrity of the Democratic Party. The photograph does not correspond with her previous belief or what she knows, so she does not accept the story as truth. Janie, therefore, assesses the truth correctly, as it turns out. Jordan, on the other hand, is pro-Republican and has a strong belief in the values of the Republican Party. She distrusts the Democratic Party and has justified reasons for doing so as Hillary Clinton, the Democratic presidential candidate, was involved in an email scandal that charged her with fraud. Jordan, therefore, has a belief that the Democratic Party is not trustworthy and so believes the fake news story. She accepts the photograph as evidence that the Democratic Party is fraudulent because it corresponds with her existing belief and what she knows, though it is, in fact, false.

The conundrum Janie and Jordan are faced with is: what should they believe or not believe? Both have provided an account of truth through their epistemic resources. Both have provided accounts of their internal beliefs and prior evidence that corresponded with their beliefs. They can justify their prior beliefs, and with which they judge the correspondence with the fake news story. While Janie used her prior 
justified beliefs to support her dismissal of the fake news story, and Jordan used the evidence of the fake news story to support her belief in the story, both were searching for alignment of the external world with their existing beliefs, which, according to Russell is one way of assessing the truth. Truth from one's perception is all that one can know. However, three immediate concerns arise from seeking the truth. One, neither Janie nor Jordan possesses knowledge. Two, determining the truth depends on the certainty and universality of the internal belief, not merely one's situated perspective of truth, which is used to assess its correspondence with the external world. Three, Russell's correspondence theory of truth seems to be similar to confirmation bias, which is widely recognized as 'the near-universal tendency to favour new evidence that confirms our existing beliefs or theories' (Gelfert 2018: 111). I will discuss these three concerns and will suggest that the narrative of confirmation bias can be understood not only as a bias, but also an effect deriving from the limitations to what knowers can know when assessing the truth of fake news in online environments.

As discussed, seeking truth in a fake news era is problematic. Neither Janie nor Jordan possessed knowledge regarding the validity of the fake ballot story. Neither one would be able to provide evidence to support their belief if required. Both relied on previously acquired true, justified beliefs to support their decision on whether to believe or not, the ballot fake news story. The second problem arising out of both knowers lacking knowledge is that their previously acquired beliefs were used as if they were universal truths, rather than situated perspectival truths as suggested by Russell. However, the problem is that neither Janie nor Jordan's previously acquired beliefs are necessarily universal truths that can be transferred to a different fake news story that appears relevant but is, none the less, different. Janie believes in the Democratic Party and their values. However, because Janie universalized her internal belief, she inherently believed that the Democratic Party and all of its party members was $100 \%$ trustworthy, and consequently refused to believe the fake news story. However, while Janie believed in those values, she failed to recognize that, perhaps, not all Democrats fully adhere to those values, and that some may be untrustworthy. Janie universalized her belief, which, were it justifiably universal, would be a proper belief on which to base another belief; it would be applicable regardless of the context. In this instance, the Democratic Party would always be considered trustworthy, and there could never be any doubts about it by anyone. As we have seen, Jordan possessed doubts that the Democratic Party was trustworthy and had good reasons for possessing those doubts. Yet Jordan fell prey to the same universality and certainty in believing the ballot fake news story. She universally applied her belief to the fake news story that the Democratic Party was corrupt. Jordan did not consider that not all Democrats are untrustworthy: she accepts it as universally true. In Janie's case, through luck, she managed to reach the correct conclusion that the story was fake. Jordan, on the other hand, did not. The lack of universal applicability of their internal beliefs means a lack of universal truth of such beliefs. Therefore, Janie's and Jordan's internal beliefs were inadequate for assessing the truth of the fake news ballot story; however, their beliefs were not inadequate because they were false beliefs, they were inadequate because of how their beliefs were used-as universal, certain truths. Consequently, arriving at the truth can occur through luck and not the ability of the knower to know the truth of fake news or not. 
We have seen that, firstly, getting knowledge is highly problematic in a fake news online environment. ${ }^{5}$ We have also seen that Russell's correspondence theory of truth can leave a knower believing that one possesses truth and a basis, therefore, for their belief. However, we have also seen that while the internal belief that one possesses may be justified and be true, it is not necessarily universally applicable to other cases that appear to correspond with it. The lack of universality means that beliefs and what appears to be evidence in the external world can correspond, but when internal beliefs are utilized universally, they are inadequate but are nonetheless used to justify the new belief. Using beliefs inadequately as a basis to form new beliefs, I suggest, stems from the inability to know, or the limits to knowing. As diligent online consumers of news, if Janie and Jordan knew their internal beliefs were not universally applicable through possessing knowledge, or if they knew that their beliefs were limited and contextual, then they may have made a different decision on whether or not to adopt the new belief that they each adopted. One can say this is nothing more than confirmation bias. However, confirmation bias describes what people tend to do; it does not address why they tend to do it. What appears to be confirmation bias and disregard for evidence may be an attempt at, or a process of, determining truth in a fake news online environment. Bonjour (1985) reminds us that to know, one must have the knowledge of a belief in one's reflective reach, that is one must have justificatory reasons within one's epistemic resources. Knowledge that is not in one's reflective reach suggests that if one cannot identify one's reasons for holding a belief, a person cannot know, and neither can s/he determine the truth of fake news in online environments. Online news consumers cannot be expected to reflect on phenomena or produce reasons that are outside of their current realm of knowledge. Consequently, determining the truth of fake news from a place of limited knowing can lead one to an enact confirmation bias and inadequately apply one's prior beliefs even though knowers may be assessing truth from Russell's correspondence theory of truth perspective, and justified in doing so. Next, I turn to discuss the coherence theory of truth in a fake news online environment.

\section{Coherence of Knowers' Belief Systems and Fake News}

In the last section, I discussed how diligent online news consumers could believe or not a fake news story based on how one's internal belief corresponds to concrete phenomena in the material world. In this section, I discuss the coherence theory. The coherence theory of truth posits that a proposition 'is true if and only if the speaker's system of beliefs includes the beliefs that warrant assertion of the proposition' (Young 2001: 91). In this view, a knower's existing belief system must contain truth conditions or propositions that warrant believing the proposition under question. When determining the truth of a proposition, the proposition is true if the truth conditions cohere with a knower's existing internal belief system. Understood another way, if a knower's belief system, the accumulation of beliefs one may have on a particular topic, are inconsistent with a proposition, the knower will not assess that proposition as true as it does not cohere with one's

\footnotetext{
${ }^{5}$ While I use one example to illustrate my point, and recognize that some news stories may be easier than others to navigate what is true or to gain knowledge about the story, I argue that the problem of fake news is even more detrimental than we may think of when we consider what we can and cannot know in online environments.
} 
consistent belief system. The coherence theory of truth does not require a knower to look externally into the world for material phenomena that cohere with one's belief as Russell's correspondence theory does; it only requires that a knower's whole internal system of belief coheres with the proposition in question. Let us return to the ballot fake news story and our two online news consumers Janie and Jordan.

Janie, as discussed, is pro-Democratic while Jordan is pro-Republican. Janie has a belief that the Democratic Party is trustworthy. When the ballot fake news story breaks, the proposition in question that suggests to Janie that the Democratic Party is fraudulent does not correspond with her beliefs in the integrity of the Democratic Party, as discussed in the last section. However, her belief in the integrity of the Democratic Party is only one aspect of her belief system. Janie also believes that the Republicans, and specifically that Donald J. Trump, are not trustworthy. Janie has seen examples of Trump in the media where Trump has contradicted himself multiple times. One such example surfaced on November 6, 2012, when Trump (2012) tweeted '[t]he electoral college is a disaster for a democracy'. Yet, on November 15, 2016, Trump (2016) tweeted '[t]he Electoral College is actually genius in that it brings all states, including the smaller ones, into play. Campaigning is much different!'. Janie has gained a belief that that Trump is untrustworthy, which becomes part of her belief system. Because of Trump's lack of coherence with respect to his beliefs, Janie assesses that Trump is not telling the truth. So her belief system also incorporates the belief that Trump is not trustworthy. She does not, therefore, believe the fake news story because she has seen evidence that Trump is untrustworthy. Janie rejects the belief asserted by the fake news story because she develops a belief that it may be Republicans, or Republican supporters behind the creation of the story, and she believes they cannot be trusted. Jordan, on the other hand, believes the fake news story. Her belief system not only includes pro-Republican attitudes, it also includes believing that the Democratic presidential candidate Hillary Clinton is untrustworthy as evidenced by the email scandal controversy, the ongoing Clinton foundation scandal, and the Trump' lock her up' (Berry 2018) campaign, which, with substantial justification, called Hillary Clinton's integrity into question. Jordan, therefore, has a belief system that supports and coheres with the formation of her belief that the ballot fake news story is true. However, while Janie and Jordan have assessed the truth and their beliefs are true, their beliefs are not universal or universally applicable. The internal true beliefs which they used as a basis for assessing the correspondence with evidence from the material world, and the coherence of the proposition in question, were specific to their context and perspective in which they initially acquired their beliefs. Given that some fake news possesses the characteristic of appearing to represent truth, even diligent online news consumers who seek facts and truth are still in a conundrum of what to believe or not believe. The question that arises next is: how ought education help online news consumers respond to the pervasive deceit of fake news?

\section{Education and Combating Fake News}

As suggested throughout this paper, teaching online news consumers about factchecking, while it ought to remain on educational agendas to help combat fake news, is still insufficient for online news consumers to reduce the uptake of, or belief in, mendacious fake news. Even diligent, fact-checking online news consumers who seek 
to understand the truth of online news, cannot overcome the inherent deceit of some fake news. As such, online news consumers are placed in peril for unknowingly believing fakes news. I suggest that one way education ought to intervene is to help online news consumers understand the limits to their own epistemological stances in relation to online fake news. Epistemological stances are, I deem, the knowledge that online news consumers each presently possesses as well as the propensities of how they use their knowledge. Not all online news consumers will possess the same knowledge, and some prior beliefs may not be knowledge at all. As what online news consumers presently 'know' depends on whether or not their prior beliefs were adequately justified to be considered knowledge. However, even with the content and legitimacy of online news consumers' prior beliefs under question, there are two inherent limitations to knowing that education can place on pedagogical agendas to help online news consumers understand. First, I outline these two limitations, and then I discuss one way that education can incorporate said aims into pedagogical agendas.

Firstly, I suggest that education can intervene to help online news consumers understand what they can and cannot know when they encounter an online news story. As discussed, to say that one knows, at minimum, one must have justified, true, belief. Understanding the requirements of knowing and realizing what one cannot know because of limited access to evidence is, I suggest a first step towards reducing one's acceptance of fake news. If Janie and Jordan realized that they could not know whether or not the fake news story is real or not, they may have sought out alternative ways of thinking about the fake news story, such as: why might it have been posted online in the first place? Education can help online news consumers understand the limits to what they can know when they seek out truth and knowledge of fake news stories as 'the facts' are not necessarily facts. To take this epistemological stance is to understand that acquiring knowledge about fake news stories merely by fact-checking does not guarantee that one will actually gain knowledge, and that access to verifiable evidence is limited and difficult to uncover.

Secondly, I suggest that education ought to help online news consumers understand the limits to the knowledge that they already possess and understand its limits of applicability. Even if one possesses knowledge and truth, these true justified beliefs may be inadequate for assessing the truth of fake news. For instance, because we understand how a bird flies does not mean we are equipped to assess how a horse runs. To adequately assess truth, we must necessarily use adequate beliefs upon which to base our assessment. Adequate beliefs are beliefs, I propose, that are not only those that are true, justified beliefs, adequate beliefs are also those that are universally applicable to all instances. Therefore, if online news consumers' beliefs are not universal, then they will need to consider whether their belief is adequate for assessing the truth of a fake news story. As fake news stories can undermine diligent online consumers of news, education ought to help online news consumers consider the limits to what they can know about fake news as well as the limits and constraints around the applicability of what they do know. Because some fake news has the power to undermine even diligent online new consumers, education ought to help online news consumers understand the limitations of what they can know when seeking to determine the truth or falseness of news online. How might education begin achieve these aims?

One strategy education can adopt in pedagogical agendas is to enhance the aims of critical thinking with additional goals of helping students understand what it means to know and the contextual constraints around some kinds of knowledge. As discussed previously, 
Bonjour (1985) tells us that we have to possess knowledge and be able to articulate reasons for our beliefs to say that we know. Yet, what we can know is limited to our own perspectival knowledge (Russell 1912) when appraising whether or not online news is true or not. Online news consumers who enact critical thinking can only evaluate or analyze that which is in their current realm of knowledge. Critical thinking agendas seeking to combat fake news can be enhanced by helping students understand their inherent contextual, epistemological constraints on uncovering the truth of fake news. One such way is to think about epistemological constraints through the lens of intellectual humility.

Intellectual humility is 'the virtue of accurately tracking what one could nonculpably take to be the positive epistemic status of one's own beliefs ${ }^{6}$ (Church and Barrett, 2017: 75). Accurately tracking is to literally track the reasons for one's belief accurately before forming a belief, holding a belief firmly, or rejecting a belief. Positive epistemic status refers to the strength of the reasons for evaluating a new belief, the firmness with which one holds one's prior beliefs, and how these are used when turning mere true belief into knowledge (Church and Barrett, 2017). Non-culpability refers to possessing positive reasons to accept a belief. If one sees evidence that one should not accept a belief, then one would be culpable if one accepted a belief; however, intellectual humility requires one to possess positive reasons before accepting a belief and not culpably ignoring evidence. Refraining from ignoring evidence is a well-known tactic for combating fake news. Critical thinking agendas seeking to combat fakes news can be enhanced by encouraging students to explicate all of their reasons for holding, accepting, or rejecting a belief. This surpasses the evaluation of online news and requires students to identify all of the reasons for one's belief in order to uncover the universality or contextual nature of one's reasons. This extension to critical thinking can assist online news consumers in evaluating whether or not online news is true or false. Uncovering the universality or contextual nature of one's belief may help reveal the limits to what one knows or how firmly one ought to hold a belief when using it as a basis to form new beliefs.

\section{Conclusion}

Thus far I have argued that fake news can undermine diligent online news consumers' ability to acquire knowledge and truth from fake news stories. I have also argued that due to limited perspectives and consequential limited knowing, diligent online news consumers can use their true beliefs inadequately and may or may not, therefore, arrive at the truth about fake news. Online news consumers can possess beliefs systems that possess truth, but due to some fake news stories appearing to be true, the appearance of the fake news story can align with online news consumers' true, justified beliefs, consequently undermining the diligent online news consumer's ability to acquire knowledge from fake news.

Possessing knowledge and truth is a vital aspect of democratic societies. Yet, fake news severely undermines diligent online news consumers' ability to acquire knowledge, and it can impede their ability to assess the truth. In a political environment of chicanery, fake news is likely to continue, to be pervasive, and to deceive some online

\footnotetext{
${ }^{6}$ Emphasis in original text.
} 
news consumers. One way education ought to intervene is to help knowers understand the limits of their epistemological stances in relation to fake news in online environments through enhancing critical thinking pedagogical strategies that seek to combat fake news. Perhaps then online news consumers may become more apt evaluators of news online with increased epistemic volition, and the conundrum of what to believe may be reduced.

Acknowledgements I wish to thank Alison MacKenzie for without her encouragement this paper would not have come to fruition.

Open Access This article is licensed under a Creative Commons Attribution 4.0 International License, which permits use, sharing, adaptation, distribution and reproduction in any medium or format, as long as you give appropriate credit to the original author(s) and the source, provide a link to the Creative Commons licence, and indicate if changes were made. The images or other third party material in this article are included in the article's Creative Commons licence, unless indicated otherwise in a credit line to the material. If material is not included in the article's Creative Commons licence and your intended use is not permitted by statutory regulation or exceeds the permitted use, you will need to obtain permission directly from the copyright holder. To view a copy of this licence, visit http://creativecommons.org/licenses/by/4.0/.

\section{References}

Audi, R. (2011). Epistemology. New York: Routledge.

Berenson, T. (2016). Donald Trump: the election's going to be rigged. Time, 1 August 2016. http://time. com/4433984/donald-trump-general-election-rigged/. Accessed 17 March 2019.

Berry, J. (2018). The Clinton foundation's history of controversy. Pacific Standard. 24 January. https://psmag. com/news/whats-going-on-with-the-clinton-foundation. Accessed 27 June 2019.

Bonjour, L. (1985). The structure of empirical knowledge. Cambridge: Harvard University Press.

Church, I. M., \& Barrett, J. L. (2017). Intellectual humility. In E. L. Worthington Jr., D. E. Davis, \& J. N. Hook (Eds.), Handbook of humility: theory, research, and applications (pp. 62-75). New York: Routledge.

Frankfurt, H.G. (1985/2005). On Bullshit. Princeton: Princeton University Press.

Dentith, M.R.X (2017). The problem of fake news. Public Reason, 8(1-2), 65-79.

Garcia, A., \& Lear, J. (2016). 5 Stunning fake news stories that reached millions. CNN Online, 2 November 2016. https://money.cnn.com/2016/11/02/media/fake-news-stories/index.html. Accessed 17 March 2019.

Gelfert, A. (2018). Fake news: a definition. Informal Logic, 38(1), 84-117. https://doi.org/10.22329/1.v38 i1.5068.

Gettier, E. L. (1963). Is justified true belief knowledge? Analysis, 23(6), 121-123.

Goldman, A. (1976). Discrimination and perceptual knowledge. The Journal of Philosophy, 73(20), 771-791.

Kirkham, R. L. (1995). Theories of truth. Massachusetts: Massachusetts Institute of Technology.

Klein, D. O., \& Wueller, J. R. (2017). Fake news: a legal perspective. Journal of Internet Law, 20(10), 5-13.

Lipton, P. (2007). Alien abduction: inference to the best explanation and the management of testimony. Episteme, 4(3), 238-251. https://doi.org/10.3366/E1742360007000068.

MacKenzie, A., \& Bhatt, I. (2018). Lies, bullshit and fake news: some epistemological concerns. Postdigital Science and Education. https://doi.org/10.1007/s42438-018-0025-4.

McIntyre, L. (2018). Post truth. Massachusetts: Massachusetts Institute of Technology.

Siegal, D (n.d.). Fake news throughout history. https://www.sutori.com/story/fake-news-throughout-history\%2 D\%2DMBnnHMXYUzyibi9S9J4XGvTd. Accessed 12 June 2019.

Russell, B. (1912/2008). The problems of philosophy. Maryland: Arc Manor.

Shane, S. (2017). From headline to photograph, a fake news masterpiece. The New York Times Online, 18 January 2017. https://www.nytimes.com/2017/01/18/us/fake-news-hillary-clinton-cameron-harris.html. Accessed 17 March 2019.

Turri, J. (2012). In Gettier's wake. In S. Hetherington (Ed.), Epistemology key thinkers (pp. 214-229). London: Continuum. 
Trump, D.J. (2016). @ realdonaldtrump. Twitter.com. https://twitter.com/realdonaldtrump/status/ 798521053551140864 ?lang=en. Accessed 26 June 2019.

Trump, D.J. (2012). @ realdonaldtrump. Twitter.com. https://twitter.com/realDonaldTrump/status/ 266038556504494082. Accessed 26 June 2019.

Vojak, B. (2017). Fake news: the commoditization of internet speech. California Western International Law Journal, 48(1), 123-158.

Young, J. O. (2001). A defense of coherence theory of truth. Journal of Philosophical Research, 26(0), 89101.

Zagzebski, L. (1994). The inescapability of Gettier problems. The Philosophical Quarterly, 44(17), 65-73. 